\title{
Letters
}

\section{Alendronate useful in treating osteoporosis}

\section{To the Editor:}

An article, "Randomised trial of effect of alendronate on risk of fracture in women with existing vertebral fracture," appears in the December 7, 1996 issue of Lancet. This study, a Fraction Intervention Trial (FIT), is a large prospective trial undertaken to assess the efficacy of a treatment in reducing the incidence of fractures in noninstitutionalized postmenopausal women with osteoporosis. Although previous studies have shown alendronate can increase bone mineral density, the study reported in the Lancet concluded that alendronate also reduces substantially the frequency of clinical vertebral fractures. Each of the women in the study had had at least one vertebral fracture at the time she was enrolled.

Only $8 \%$ of the patients in the alendronate group had at least one new vertebral fracture compared with $15 \%$ of the patients in the placebo group. Fortyseven percent fewer patients in the alendronate group had at least one new vertebral fracture compared with subjects in the placebo group. In addition, $90 \%$ fewer patients in the treatment group had multiple vertebral fractures compared with patients in the placebo group.

Similar results were seen when nonvertebral fractures were examined. A $51 \%$ reduction in hip fracture risk was found in patients in the alendronate group and a $48 \%$ reduction in wrist fractures.

Because this study included only women who had vertebral fractures at recruitment, these women were thought to be at a substantially higher risk of having subsequent vertebral and nonvertebral fractures than women without fractures. No differences in the rate of adverse events were noted between the two groups. Likewise, no significant difference was found in the frequency of esophagitis or upper gastrointestinal symptoms between the women in both groups.

Thus, this study, involving more than 2000 primarily white women with lowbone density and at least one vertebral fracture, found alendronate to be welltolerated. Furthermore, this drug substantially reduced the frequency of morphometric and clinical vertebral fractures, as well as other clinical bone fractures. By reducing the frequency of fractures, alendronate could also decrease the disability associated with osteoporotic fractures.

\section{Bernard R. Rubin, DO}

Professor of Medicine

Chief, Division of Rheumatology

University of North Texas Health Science

Center at Fort Worth

Fort Worth, Tex

\section{New members}

Abessinio, Andrea M, KCOM '89; Suite 5, 20861 Mack Ave, Grosse Pt Woods, MI 48236

Alevizos, John, CCOM' 90; 7569 E Bridgewood Dr, Anaheim, CA 92808-1407

Bachove, Stephen W, PCOM '73; No. 111, 503 Polaris Loop, Casselberry, FL 32707-6801

Bartz, Nicholas W, UOMHS '81; PO Box 1392, Jackson, MI 49204-1392

Bellovich, Keith A, MSUCOM '89; No. 150, 22201 Moross, Detroit, MI 48236

Bergquist, Michael Victor, UOMHS '87; 4444 Kalamazoo, Kentwood, MI 49508

Brixey, James R, UHSCOM '68; No. 101, 1500 E Downing, Tahlequah, OK 74464-3234

Brodzik, Lee Ann, NYCOM '85; Apt A209, 903 Parkview Dr, King of Prussia, PA 19406-1019

Cassani, John Joseph, OSUCOM '80; 3967 S McCarran Blvd, Reno, NV 89502 7510

Castle, Stephen P Maj, UOMHS '87; Suite 370, 1800 15th St, Greeley, CO 80631

Citta-Pietrolungo, Thelma Jean, PCOM '86; 2591 Fenwick Rd, University Hts, $\mathrm{OH}$ 44118-4426

Cubina, Maria, NYCOM '89; 129 Birch Hollow Dr, Bordentown, NJ 085054235

Daly, Stephen J, UOMHS '76; 6 Jasmine Ln, Sicklerville, NJ 08081-4106

Dawson, John M Lt, KCOM '81; 2612 W Pine Lake Rd, Columbiana, $\mathrm{OH} 44408$ 9770

Dean, David A, UHSCOM '92; PO Box 10041, Ft Irwin, CA 92310-0041

Donaldson, John R, UNTHSC '89; 4105 Kirkman St, Lake Charles, LA 70607 4603

Duckett, Laurie A, OSUCOM '89; 1844 E 15th Street, Tulsa, OK 74104-4611

Frohlich, Douglas J, CCOM '85; 7108 N Crawford Ave, Lincolnwood, IL 606462304

Gilreath, V Shearman, UHSCOM ' $73 ; 511$ Elmwood, Dearborn, MI 48124-1661

Goldstein, Martin Barnet, CCOM '59; No. 2506, 2400 Chestnut St, Philadelphia, PA 19103-4316 